\title{
Conceptual Capacities in Perception
}

\author{
John McDowell \\ University of Pittsburgh
}

1. Our perceptually based beliefs are intelligible as manifestations of rationality. We can make sense of them by putting them in an explanatory nexus with perceptual experience. If someone has a perceptually based belief, she believes something because her experience reveals to her, or at least seems to reveal to her, that things are as she believes them to be. And that "because" introduces an explanation that depends on the idea of rationality in operation.

I think crediting our perceptual experience with this rational significance is a fundamental insight of empiricism. I have argued that in order to accommodate it, we need to conceive our perceptual experience as an actualization, in sensory consciousness, of conceptual capacities. ${ }^{1}$

This conception of our perceptual experience bears a resemblance to Kant's conception of empirical intuitions. In the first Critique $^{2}$ (especially clearly in the Transcendental Deduction), Kant conceives empirical intuitions as configurations in sensory receptivity that are categorially structured. For Kant, intuitions belong together with judgments in this respect: what makes their objective purport possible is that they have categorial unity. To put a Kantian thought in a contemporary idiom, the content of intuitions is of the same general kind as the content of judgments. And of course the content of judgments is conceptual.

This echo of Kant brings out a connection with the theme of creativity. Kant introduces the understanding, the seat of conceptual capacities, by contrasting it with the receptivity of sensibility. He describes the understanding as "the mind's power of producing representations from itself, the spontaneity of knowledge" (A51/B75). Even more directly, he says that concepts are "based on the spontaneity of thought" (A68/B93).

\footnotetext{
${ }^{1}$ See John McDowell, Mind and World, Cambridge, Mass. 1994; and McDowell, "Having the world in view: Sellars, Kant, and intentionality”, Journal of Philosophy (1998), pp. 431-91.

${ }^{2}$ Immanuel Kant, Critique of Pure Reason, translated by Norman Kemp Smith, London 1929.
} 
So his conception of empirical intuitions links their objective purport, their serving to make objects immediately present to us, with a capacity he attributes to us for spontaneous self-determination in thought.

I shall come back to this. But first I am going to spend some time elaborating the conception of perceptual experience that credits this role to the spontaneous understanding. The main task is to explain the relevant idea of conceptual capacities. That will require first saying something about the idea of rationality.

2. I said that perceptually based belief is linked to experience by an explanatory nexus that depends on the idea of the workings of rationality. The notion of rationality I mean to invoke here is the notion exploited in a traditional line of thought to make a special place in the animal kingdom for rational animals. It is a notion of responsiveness to reasons as such.

That wording leaves room for responsiveness to reasons, though not to reasons as such, on the other side of the division drawn by this notion of rationality between rational animals and animals that are not rational. Animals of many kinds are capable of, for instance, fleeing. And fleeing is a response to something that is in an obvious sense a reason for it: danger, or at least what is taken to be danger. If we describe a bit of behaviour as fleeing, we represent the behaviour as intelligible in the light of a reason for it. But fleeing is not in general responding to a reason as such.

For that idea to be appropriate in this connection, we would need to be considering a subject who can step back from an inclination to flee, elicited from her by an apparent danger, and raise the question whether she should be so inclined - whether the apparent danger is, here and now, a sufficient reason for fleeing. If what an animal does flows immediately from its natural motivational tendencies, with no room for this kind of reflection, its behaviour is determined by its nature. That is not to deny that its behaviour is voluntary; and an animal, qua producer of voluntary behaviour, is not to be simply identified with the motivational impulses that come naturally to it. But in this kind of case the distinction between the behaving animal and its motivational impulses has no particular importance. There is no particular point in saying it is the animal itself that determines what it does. In contrast, consider a person who steps back from an 
inclination to flee that comes naturally to her, and decides that the circumstance that elicits the inclination is a sufficient reason for fleeing. If she then acts on that reason, she is self-determining in her action.

This is only an example, to give the flavour of the conception of rationality I mean to appeal to. Obviously reasons for acting are not exhausted by circumstances of a sort that would naturally prompt inclinations, when those circumstances are transformed into reasons, able to be responded to as such, for a subject who can raise the question whether that is what they are. And of course there are also reasons for belief.

Let me stress that what matters is the capacity to step back and assess whether putative reasons warrant action or belief. If someone actually steps back, of course that shows she has the capacity to do so. But if the capacity is present without being exercised, we have in view someone who can respond to reasons as the reasons they are. And rationality in the sense I am explaining may be actually operative even though the capacity to step back is not being exercised. Acting for a reason, which one is responding to as such, does not require that one reflects about whether some consideration is a sufficient rational warrant for something it seems to recommend. It is enough that one could.

Consider someone following a marked trail, who at a crossing of paths goes to the right in response to a signpost pointing that way. It would be absurd to say that for going to the right to be a rational response to the signpost, it must issue from the subject's making an explicit determination that the way the signpost points gives her a reason for going to the right. What matters is just that she acts as she does because (this is a reasonintroducing "because") the signpost points to the right. (This explanation competes with, for instance, supposing she goes to the right at random, without noticing the signpost, or noticing it but not understanding it.) What shows that she goes to the right in rational response to the way the signpost points might be just that she can afterwards answer the question why she went to the right - a request for her reason for doing that - by saying "There was a signpost pointing to the right". She need not have adverted to that reason and decided on that basis to go to the right. 
3. I find it helpful to connect the idea of conceptual capacities with this notion of rationality. I use the idea of conceptual capacities in a way that is governed by this stipulation: conceptual capacities in the relevant sense belong essentially to their possessor's rationality in the sense I am working with, responsiveness to reasons as such.

The primary context for the idea of responsiveness to reasons as such is reasoning: an activity in which someone explicitly considers what to believe or what to do, and takes reasons into account in determining her belief or her action. Capacities can be at work in operations of rationality, and so can be conceptual capacities in the sense of my stipulation, only in subjects who can exercise those capacities in reasoning. The ability to step back and assess whether putative reasons really are reasons, which I exploited when I introduced the idea of responsiveness to reasons as such, is part of the ability to reason. So to invoke reasoning is just to provide a label for the context in which I am putting the idea of responsiveness to reasons as such.

If an animal has in its repertoire behaviour appropriately conceived as fleeing, it must be able to discriminate (perhaps not very accurately) between situations that pose danger to it and situations that do not. But given my stipulation, this ability to discriminate does not suffice for having the concept of danger. The concept requires a subject who can respond to dangerousness as the reason it is. And that requires in turn the ability to take dangerousness into account in reasoning.

Now that I have introduced reasoning, I can put a point I have made already like this: cases in which one engages in reasoning do not exhaust the scope of one's responsiveness to reasons as such. Consider again the person who, without taking thought as to what to do, goes to the right in rational response to a signpost that points that way. Up to a point, her behaviour, unreflective as it is, is like going to the right on the part of an animal that has been trained to go to the right in response to objects with a certain shape. Such an animal has acquired an ability to discriminate between things that have that shape and things that do not. But as with the ability to discriminate between situations that pose danger and situations that do not, this does not suffice for having the concept of things that point to the right. Having the concept requires the ability to take something's falling under it into account in reasoning. Our rational subject has that ability, though she does not exercise it on the occasion we are considering, when she goes 
to the right without reasoning to a decision to do so. And the conceptual capacity that her possession of the ability entitles us to attribute to her, with the concept of things that point to the right as its content, is operative also in the unreflective response we are considering: a response, not involving reasoning, to a signpost's pointing to the right as a reason for going to the right. Conceptual capacities in the relevant sense are at work not just in reasoning but, in general, in responding to reasons as such, whether or not it takes the form of explicitly drawing conclusions from reasons in forming beliefs or in acting.

4. I have connected responsiveness to reasons as such, and hence conceptual capacities, with reasoning. That is to put the relevant notion of rationality in the context of a notion of inference, understood broadly enough to cover acting in consequence of practical reasoning as well as coming to believe something in consequence of theoretical reasoning. If someone believes something or acts in a certain way for a reason, she need not have reached her belief or her action by an inferential step. But I have so far considered only operations of rationality involving structures of a kind that could characterize theoretical or practical inferences, from reasons to beliefs or actions.

But my aim was to spell out how the idea of rationality is in play when we explain perceptual beliefs in terms of experience. And here the notion of inference gets no grip. When one acquires a belief in this way, one comes to believe that things are as one's experience reveals, or at least seems to reveal, that things are. The content that the explanation attributes to the experience is the same as the content of the belief explained, not a premise from which it would make sense to think of the subject as having reached the belief by an inferential step. ${ }^{3}$

This does not undermine the thought that these explanations make beliefs intelligible as results of the subject's rationality at work. And here too, this is rationality in the sense that separates rational from non-rational animals, the sense I have tried to capture in terms of responsiveness to reasons as such. (This is widely controverted, on the ground that it prevents us from accommodating the way non-rational animals come to know about things through their senses. It should be clear later why this is wrong.)

\footnotetext{
${ }^{3}$ This formulation leaves room for acknowledging that the experience has content over and above what is invoked in explaining the belief.
} 
One can have an experience that reveals to one that things are thus and so without coming to believe that things are thus and so. One need not avail oneself of every rational entitlement one has. Consider a case in which one is misled into mistrusting one's experience. One does not believe it is revealing to one how things are, but in fact it is doing just that.

A belief-acquisition explicable as rational in the light of an experience is a case of rationality at work, even though, as I have urged, this mode of operation of rationality is not capturable by a structure that could characterize an inference. The belief is intelligible in terms of a rational entitlement to it supplied by the experience. And since having the experience constitutes a rational entitlement to belief whether or not one acquires the belief it entitles one to, that same rationality must be at work in one's having the experience at all, even if one does not acquire the belief it entitles one to. So, applying the stipulation to this case: if our notion of an experience is to be capable of playing the role it plays when we explain perceptually based beliefs as manifestations of rationality, we must understand having such an experience - being in possession of such an entitlement - as itself, already, an actualization of the conceptual capacities that would be exercised by someone who explicitly adopted a belief with that content. ${ }^{4}$

This is a kind of actualization of conceptual capacities whose members are cases of perceiving, or at least seeming to perceive, that things are thus and so. When we explain someone's believing that things are thus and so in terms of the fact that her experience merely seems to reveal to her that things are thus and so, the explanation depicts the belief as a result of rationality leading its possessor astray, or at best equipping her with a true belief by a fortunate accident. But when we explain someone's believing that things are thus and so in terms of her perceiving that things are thus and so,

\footnotetext{
${ }^{4}$ Clearly I am not using the term "entitlement" as Tyler Burge does, in "Perceptual entitlement", Philosophy and Phenomenological Research (2003), pp. 503-48. Burge does not locate entitlement in the context of a notion of self-determining rationality. Indeed he discourages the traditional divide between rational and non-rational animals, which he accuses of leading to "hyper-intellectualization" (pp. 503-4). Astonishingly, Burge writes (p. 504, n. 1) as if his "introduction" of "entitlement" used his way, in papers from 1993 and 1995, gave him some kind of patent on the term, so that he can complain that different uses are "indiscriminate". My use is not indiscriminate, and the word, ordinary English as it is, is anyone's property. It can be used with complete naturalness in any "normative" epistemology. I shall consider the accusation of "hyper-intellectualization" in $\mathrm{n} .11$ below.
} 
we are displaying the belief as a result of this kind of operation of rationality in its ideal form.

5. It is important that the connection between conceptual capacities and rationality is a stipulation. It is not that there is a universally shared idea of conceptual capacities, which determines a subject matter about whose properties people disagree. The notion of the conceptual can be used in a variety of ways, for a variety of purposes.

It is also important that the notion of responsiveness to reasons as such leaves room for responding to reasons, though not to reasons as such, on the other side of the divide between rational animals and animals that are not rational. And responding to reasons implies awareness of what is responded to. ${ }^{5}$

If someone wants to say an animal with fleeing in its repertoire is thereby shown to have the concept of danger, I need not object. This is to use the concept of a concept otherwise than in accord with my stipulation. But that is all right, provided that we keep track of the divergence, and do not mistake it for a substantive dispute about a supposedly common subject matter.

On this way of talking, a concept of danger is in play in any awareness, or (to accommodate the possibility of mistakes) seeming awareness, of danger. And using the concept of a concept like this affords a way of insisting on a good point: that to be able to be aware of danger, an animal need not be rational, in the sense that figures in the traditional divide between rational animals and others. Obviously this generalizes to other objects of animal awareness.

This is fine by my lights. As I said, the point is a good one. It definitely contradicts the idea that if an animal's fleeing is not a response to a reason as such, the animal's differential responsiveness to danger can be no more than a responsive disposition, in a sense that is not restricted to the discriminating capacities of sentient beings. On this view, the differential responsiveness to danger manifested in an animal's capacity for fleeing would not license crediting the animal with being able to be aware of

\footnotetext{
${ }^{5}$ The general point here is that stressing the distinction between rational and non-rational animals is consistent with insisting on a substantial continuity across the divide. Burge, op. cit., seems oblivious to this possibility. This underlies, among other things, an uncomprehending treatment of Wilfrid Sellars and philosophers influenced by him, at pp. 526-30.
} 
danger, any more than, say, iron's differential responsiveness to moisture in its surroundings - a disposition to rust if there is moisture and not to rust if there is not licenses supposing bits of iron can be aware of the presence of moisture. ${ }^{6}$ I think this should be rejected out of hand. It flies in the face of common sense about how the behaviour of living animals is to be understood.

But to preserve common sense about animal awareness, we do not need to detach conceptual capacities from responsiveness to reasons as such. My stipulation does not require debunking the idea of awareness that is not conceptual. The restriction effected by my stipulation applies only to awareness that figures in the operations of rationality in the demanding sense. And there is no need to suppose the capacity to figure in the operations of rationality is an element in the very idea of awareness. ${ }^{7}$

\section{For a substantive objection to my proposed conception of our perceptual experience,} as opposed to the merely terminological divergence I have just been discussing, we need to consider a position that accepts the stipulative identification of conceptual capacities in terms of their potential role in reasoning, but disputes my claim that conceptual capacities, so understood, are operative in our perceptual experience.

Many people have taken this line. A commonly felt incredulity takes this form: if one supposes, as I do, that the content of our experience is conceptual, in a sense in which

\footnotetext{
${ }^{6}$ Consider Robert Brandom's account of observational knowledge. Brandom's account implies that if we start with capacities for observational knowledge and subtract conceptual capacities, in a demanding sense that can be explained in terms of a connection with rationality, the remainder is nothing but reliable differential responsive dispositions - dispositions of a kind possessed not only by animals but also by inanimate objects such as thermometers or, even more simply, collections of iron filings. See chapter 4 of Robert B. Brandom, Making It Explicit: Reasoning, Representing, and Discursive Commitment, Cambridge, Mass. 1994.

${ }^{7}$ Michael Ayers, in "Sense experience, concepts, and content - objections to Davidson and McDowell", in Ralph Schumacher, ed., Perception and Reality: From Descartes to the Present, Paderborn 2004, pp. 23962, says I am equivocal about perceptual awareness on the part of non-rational animals. (See p. 239. The claim is spelled out at p. 261. Ayers says my thinking tends in the direction of a Cartesian view of "animals", though - the other side of my supposedly equivocal stance - my exposition is "larded with disclaimers".) This reflects his finding it obvious that what perceptual awareness is for rational animals cannot be different in kind from what it is for non-rational animals. The result is that when I deny that nonrational animals have, in the way of perceptual awareness, what we have, he cannot hear that except as implying that they do not have perceptual awareness at all. This is an example of the bad effects of bringing one's own sense of what is obvious to reading someone else. It can make for being unable to hear what someone is saying. And it is especially bad practice when, as in this case, the target of the reading is precisely questioning the sense of what is obvious that controls the reading. Ayers's suggestion that my thinking tends towards a Cartesian denial of consciousness to non-rational animals is groundless.
} 
the conceptual is connected with rationality, one cannot do justice to the sensory way in which perceptual experience discloses reality to us.

For instance, Michael Ayers, in arguing that the content of sense experience, including ours, is non-conceptual, stresses "the way things are presented in experience, the sensory mode of presentation ...". He identifies the claim that this is non-conceptual with the claim - which he represents as sheer common sense - "that the way the world is presented in experience is not quasi-linguistic". ${ }^{8}$ His thought, then, is that if our experience were conceptual, it would present the world in a quasi-linguistic way, and that is inconsistent with the obvious fact that experience presents the world in a sensory way.

But what I recommended was a conception of our experience as actualization of conceptual capacities in sensory consciousness. To adopt that conception of our experience is to accept, indeed to insist, that our experience presents the world in a sensory way. Ayers is disallowing the very possibility of supposing, as I do, that a conceptual mode of presentation might itself be a sensory mode of presentation.

Ayers equates the claim that our experience has conceptual content with the claim that it presents the world in a quasi-linguistic way. That might seem to justify excluding the possibility that a conceptual mode of presentation might be a sensory mode of presentation. But in so far as the equation seems to justify the exclusion, it is tendentious. What is right about the equation is this: it is plausible that the ability to step back from considerations and raise the question whether they constitute reasons for action or belief, which I have invoked as a necessary context for conceptual capacities in the sense of my stipulation, is coeval with command of a language. So only speakers can have conceptual capacities in the sense of my stipulation. But this does not justify claiming that my conception of our experience represents the experienceable world as a text, or, in Arthur Collins's image, that I am committed to a picture in which our experience comes as it were with subtitles - as if the conceptual way in which, according to me, our experience purports to disclose the world to us would be an extra feature of it, additional to its sensory character. ${ }^{9}$

\footnotetext{
${ }^{8}$ Op. cit., p. 249.

${ }^{9}$ See Arthur W. Collins, "Beastly experience”, Philosophy and Phenomenological Research (1998), pp.

375-80, at p. 379. For the idea of experienceable reality as a text, see Ayers, op. cit., p. 251, n. 23.
} 
Collins's image helps to make vivid a specific form often taken by the claim that conceptual content cannot accommodate the sensory way experience presents things. There is no plausible elaboration of the image in which subtitles could capture, say, all the differences of shade that normal colour experience finds in the visible world. But this is no problem for my proposal, because the image of subtitles does not fit my proposal. Our visual experience can present a shade of colour that is as determinate as our ability to discriminate shades can make it. A determinate shade is present in a sensory way to the subject of such an experience. But its sensory presence to her is an operation of a capacity that belongs to her responsiveness to reasons as such, and hence is conceptual in the sense of my stipulation. This is reflected in the fact that to enjoy the experience is to have a rational entitlement to a belief that the thing has just that shade. In the ideal case, it is an entitlement that amounts to the subject's being in a position to know, by way of an operation of her rationality in the demanding sense, that the thing has just that shade..$^{10}$

In disallowing my proposal that actualizations of conceptual capacities can present things in a sensory way, Ayers assumes a sharp separation between the sensory and the intellectual, as I shall put it to avoid that tendentious implication.

But such a separation is not uncontentiously correct. If a dualism of intellect and senses is merely assumed, it is question-begging to exploit it against me. And what justification can there be for the dualism? It is taken for granted in the empiricist tradition, but in this dialectical context that would be an unimpressive basis for defending

\footnotetext{
${ }^{10}$ In Mind and World (pp. 56-60), I connected these fine-grained conceptual capacities with the ability to capture a shade of colour (say) by using a demonstrative expression that depends for its significance on an experience in which something is seen as having that shade of colour. I wrote of expressions like "that shade". ("Coloured thus" would have been better, for reasons that come out in my response to Christopher Peacocke in "Reply to commentators", Philosophy and Phenomenological Research (1998), pp. 403-31, at pp. 414-7.) Ayers, op. cit. p. 260, argues that on this account, the shade would have to be presented in experience independently of a conceptual capacity whose content could receive linguistic expression in that way; so it would have to be presented in experience non-conceptually. But there is no basis for this.

Certainly the shade must be presented in experience anyway, for its presence to be able to help determine the significance of the demonstrative expression. But that is consistent with its presence in experience being an operation of a conceptual capacity - one that, thanks to the shade's presence in experience (that is, thanks to this operation of the conceptual capacity it is), can be captured by the demonstrative expression. Ayers's impression to the contrary depends on mishandling the connection between conceptual capacities and language. (In effect, he is allowing the subtitles picture to confuse him.) He proceeds as if I had to suppose the content in question acquires a conceptual form only when language is actually used, in that demonstrative form, to express it. The intelligibility of the demonstrative form would require that the content was already there - hence, on this view, before the content acquired conceptual form. But it is enough for the content to be conceptual that it can be given that linguistic expression. It does not become conceptual only when actually given that linguistic expression.
} 
it. So much the worse for the empiricist tradition, we might say. Resting content with a dualism of the sensory and the intellectual betrays a failure of imagination about the possibilities for finding the rational intellect integrally involved in the phenomena of human life. ${ }^{11}$ We should argue in the other direction. Actualizations of conceptual capacities, capacities that belong to their subject's rationality, can present things in a sensory way, and that gives the lie to the dualism.

7. Donald Davidson notoriously claimed that "nothing can count as a reason for holding a belief except another belief". ${ }^{12}$ I objected that this does not accommodate the role of experience in making beliefs rationally intelligible. Experiences are not beliefs. But I suggested we can preserve an insight from Davidson's slogan, by saying nothing can count as a reason for a belief except something with conceptual form. ${ }^{13}$

Ayers objects that there is nothing worth preserving from Davidson's slogan. All kinds of things can be reasons for belief. A photograph can be a reason for a belief about the assassination of John F. Kennedy. A perceived zebra can be a reason for a belief about what zebras look like. And so on. ${ }^{14}$

Of course that is right, about a familiar way of using the notion of a reason. But this is a cheap victory, which leaves the spirit of Davidson's slogan untouched.

In the cases the slogan fits (which do not include perceptually based beliefs), Davidson's claim is obviously not that one bases a belief on one's believing something else - as if, in Ayers's example, one concluded that Kennedy was shot by someone on the ground from the fact that one believes a photograph shows someone shooting at him from the ground. It is what one believes, not one's believing it, that is one's reason in the

\footnotetext{
${ }^{11}$ Burge thinks stressing the self-determining rationality of rational animals leads to "hyperintellectualization" in epistemology (op. cit., pp. 503-4). But insisting that rational animals are special leads to the excess of intellectualism he rightly deplores only in conjunction with a dualistic separation of the rational intellect from the senses, or more generally from the cognitively relevant endowments we have by virtue of our animal nature. The accusation does not fit what I am urging. Without the dualism, we need not discount the biologically anchored cognitive "norms" Burge discusses. They are surely relevant to understanding the norms that govern the cognitive conduct of rational animals. But we do not fall into "hyper-intellectualism" if we insist that being subject to the latter norms is characteristic of cognition with a categorially different nature.

${ }^{12}$ Donald Davidson, "A coherence theory of truth and knowledge", reprinted in Davidson's Subjective, Intersubjective, Objective, Oxford 2001, pp. 137-57, at p. 141.

${ }^{13}$ See Mind and World, pp. 141, 143-4.

${ }^{14}$ See op. cit., pp. 243-4, 248-9.
} 
sense Davidson is concerned with. And this is easily extended to make room for the idiom Ayers exploits. In that idiom, one describes as reasons items that belong to the subject matter of beliefs that are reasons in Davidson's sense. That is the sense in which the photograph is a reason for a belief about the assassination.

If we abstract Davidson's slogan away from the effects of his blind spot about the possibility of crediting experience with rational significance, we can understand its point on these lines: the capacities at work when one's rationality is operative must be capacities that belong to one's rationality. How could that be wrong? Certainly one can adduce a photograph as evidence for a belief about the assassination, not just out loud, trying to persuade someone else, but also in deciding what to think. The point of Davidson's slogan is not to deny that, but to claim that the photograph can play that role, a role in an operation of rationality, only by figuring in the content of an actualization of capacities that belong to one's rationality: that is, capacities that are conceptual in the sense of my stipulation. I explained earlier (in §4) how this abstract core of Davidson's thought carries over into what we need to say in order to acknowledge the rational significance of experience, as Davidson does not. Ayers's reminder about what he calls (rightly so far as it goes) "a basic kind of reason-giving" (op. cit., p. 243) does not address these considerations. It leaves them completely unscathed.

8. Let me go back now to the connection with the theme of creativity.

To introduce the notion of rationality I wanted to work with, I contrasted fleeing as the immediate outcome of a natural impulse with fleeing as the result of deciding that a circumstance that is tending to elicit an impulse to flee constitutes a sufficient reason to do so. In the second case, fleeing is not merely voluntary but determined by the agent herself. Generalized, this contrast yields something on these lines: what is special about rational animals is that they are capable of self-determination, in thought and action. A rational animal has the capacity to be in control of its life, to live in such a way that its life is something of its own making. If a life is led with the freedom that rationality makes possible, there is some point in comparing it to a work of art that the subject is engaged in creating. 
Of course what rationality confers is only the capacity to live a life that is one's own in the sense I am gesturing at. To what extent the capacity is exercised, and in which regions of life, depends on all kinds of factors. The conditions under which the potential for freedom can be realized are an important topic for philosophy.

Now what I have proposed is that capacities that belong to this special potentiality of rational animals, capacities for self-determination in thought, are essentially involved in the acquisition by rational animals of perceptually based beliefs.

We need to be careful about how the idea of a capacity to be in charge of one's life fits in this context. Once one has determined such things as the direction of one's gaze, it is not under one's control how one's experience purports to reveal things to be. Moreover, coming to believe something on the basis of experience is not in general happily conceived as deciding what to think. It is true that there are cases in which, with more or less effort, one can refuse to accept that things are as they, say, look to be. If one is familiar with the Müller-Lyer illusion, one inhibits the tendency to judge that one of the two lines is longer than the other, even though, however familiar one is with the illusion, one line goes on looking longer. But perceptual experience can bring facts into plain view. And when that is the appropriate thing to say, it would be absurd to talk of deciding what to think, as if one exercised an option. One does not choose to accept that things are the way one's experience plainly reveals that they are.

We might put this by saying there is a sense in which perceptual experience can compel belief. But because capacities for rational self-determination are at work in one's being subject to this compulsion, it does not detract from one's being in rational control of one's life. Compare the sense in which one can be compelled to accept the conclusion of a cogent argument whose premises one is unshakeably committed to. One does not sacrifice one's freedom if one acquiesces in the authority of what one recognizes as compelling reasons. Recognizing reasons as compelling is itself an exercise of one's capacities for rational self-determination. If one offers no resistance when one's beliefs take the form reason requires them to take, one is not handing over that region of one's 
life to an alien force. One is not abdicating from the responsibility to be in rational control of one's thinking. ${ }^{15}$

9. Ayers objects to the idea that empiricism cannot credit perceptual experience with a content that goes beyond sensations. He invokes a position with "a respectable empiricist ancestry" (he cites Hobbes), according to which "what is 'given' in a sensation of a green light flashing ... is just that, a green light flashing". The sensory states enjoyed by a perceiver themselves already have intentional content, and the sense in which perceptual beliefs are grounded in sensation is that they derive their intentional content from the intentional content of the sensory states they are based on. "That, on this view, is what believing one's senses is. No inference is involved, and there is no intermediary. We just accept what the senses conjointly give."16

I think this is just the shape an acceptable empiricism must have. It is precisely to make room for a view with this shape that I urge the conception of our experience that Ayers resists. It is precisely to provide for the thought that perceptual experience can directly open us to the world that I claim we must see experience as an actualization of conceptual capacities, capacities that belong to our special character as rational animals.

As I have explained, this is not to deny that non-rational animals become informed or misinformed through their senses, about features of reality that matter to them. It is just to insist on a difference between that and coming to know things through perception as we do, in an operation of rationality in the strong sense, responsiveness to reasons as such.

\footnotetext{
${ }^{15}$ Richard Rorty suggests that conceiving thought as answerable to its subject matter represents the world as a secular counterpart of an authoritarian deity. See, e.g., "Solidarity or objectivity?", in his Objectivity, Relativism, and Truth, Cambridge 1991, pp. 21-34; and "The very idea of human answerability to the world: John McDowell's version of empiricism”, in his Truth and Progress: Philosophical Papers, vol. 3, Cambridge 1998, pp. 138-52. This is meant to show that regarding objectivity as a constitutive ideal of thought flouts the obligation to think for oneself, which is part of the content of the obligation to live one's own life. I think the considerations I am sketching here show that this position of Rorty's depends on misinterpreting the obligation to think for oneself. The obligation to think for oneself cannot require one to emancipate one's thinking from being controlled by good reasons. And when one's experience reveals to one how things are, one is in possession of an excellent reason to think things are that way. Rorty is right to recoil from various extremist forms of realism, but he is wrong to let that lead him into an undiscriminating attack on all forms of the idea that objectivity is a constitutive goal of thought.

${ }^{16}$ All the quotations in this paragraph are from op. cit., p. 241.
} 
Non-rational animals become informed or misinformed through the unmediated functioning of their senses. It would be a failure of ear if one found it appropriate to describe them as believing their senses or accepting what their senses give. Such talk fits belief-formation by subjects who can refuse to believe their senses - belief-formation intelligible as rationality, in the sense of responsiveness to reasons as such, at work.

As I have urged, seeing our acquisition of perceptual beliefs as rationality at work does not imply that we always come to such beliefs by deciding what to think. Normally we arrive at our perceptually based beliefs without reflection. But what we do without reflection can be described as believing our senses or accepting what our senses give only because it is a manifestation of our rationality in the demanding sense, and hence, as I have explained, an actualization of capacities that belong to our rational understanding, capacities we do not share with non-rational animals.

10. Ayers's resistance to the idea that conceptual capacities are operative in our perceptual experience is largely driven by his hostility to the idealism he takes it to open into.

Now there is justice in the thought that the idea can seem to work only in the context of an idealism. And I think this is central to a supposed ground, not unique to Ayers, for disbelieving that capacities that essentially belong to our potential for selfdetermination can be in play in what is supposed to be our sensory reception of reality. But here we need a distinction Ayers makes nothing of.

Any idealism with a chance of being credible must aspire to being such that, if thought through, it stands revealed as fully cohering with the realism of common sense. ${ }^{17}$ Kant, for instance, has that aspiration for his transcendental idealism. This shows in his claim that it coincides with empirical realism. However, because of the way he treats the forms of our sensibility, he fails to entitle himself to that claim. In his picture, the world as we experience it seems, in respect of its apparent spatial and temporal organization, to

\footnotetext{
${ }^{17}$ In Notebooks 1914-1916, Oxford 1961, p. 85, Wittgenstein writes that "idealism leads to realism if it is strictly thought out”. (At Tractatus Logico-Philosophicus, London and Henley 1961, §5.64, the coincidence with realism is directly credited to solipsism, which figures in the route from idealism to realism in the Notebooks.)
} 
be a mere reflection of self-standing features of our subjectivity. So the aim at a coincidence with realism fails.

Of course particular failures cannot undermine the very idea of an idealism that coincides with common sense. Ayers, however, cannot see anything idealism could be, apart from a position that represents features of the structure of reality (so called, we would have to say) as projections from characteristics of a self-standing subjectivity, as Kant's idealism does in spite of his aspiration for it.

In my Mind and World, I argue that the conceptual content of a perceptual experience can be, and if all goes well is, something that is the case, an element in the world. We can see experience as directly taking in part of the world, because the world, understood as everything that is the case, is not outside the sphere of the conceptual. I remark that this can seem to be "a sort of idealism, in the sense in which to call a position 'idealism' is to protest that it does not genuinely acknowledge how reality is independent of our thinking" (p. 26). But I work to dislodge such an appearance.

Now Ayers quotes from the sentence I have just quoted from (op. cit., p. 252). But he ends his quotation before the gloss in which I specify the sort of idealism I want to disown. Evidently he thinks the gloss is redundant; as he sees things, idealism just is a position that insufficiently acknowledges the independence of reality.

This has consequences. When I reject the accusation that I represent the world as a projection from our subjectivity, Ayers thinks I must be denying that "the form of judgement structures the world as experienced and known" (op. cit., pp. 254-5). He thinks I must conceive the world as standing to our thought and talk in a large-scale counterpart to the relation in which, say, a zebra might stand to our thought and talk about it. A zebra can be described, but that is no reason to suppose the zebra itself has a form it shares with a description, or with the thought a description expresses. Just so, Ayers thinks I think, with the world. (Anything else would be idealism, and I have declared that I am against that.) And then, if what I say about the world is "no more than a way of putting the platitude that the world and things in it are describable" (op. cit., p. 253), Ayers cannot see how I can disallow a parallel move about experience. No doubt what experience gives us can be expressed in propositional or conceptual form, but that is 
no reason to suppose experience itself has conceptual form, any more than zebras do, and hence any more than the world does, on the conception he thinks he finds in me.

Here Ayers has been led into a misreading by his assumption that any notion of the world as itself conceptually structured must imply what I explicitly disavow, that the world is a mere reflection of a self-standing subjectivity. In the passage he is considering, I discuss the remark "The world is everything that is the case", the first remark in Wittgenstein's Tractatus. I urge that we should not take it to express "a grand ontological or metaphysical vision”, to use Ayers's words (op. cit., p. 252) My point is that we should understand the remark as spelling out, truistically, the content of an unimpeachable way to use the notion of the world. My point is not, as Ayers supposes, that we should somehow not mean it when we say the world is everything that is the case. And if we do say that and mean it, we conceive the world, not in the way Ayers thinks I must conceive it, as a totality of the describable things - zebras and so forth - that there are (as we say) in it, but as, precisely, everything that can be truly thought or said: not everything we would think about if we thought truly, but everything we would think.

This is an idealism in an obvious sense. On this conception, the world itself is indeed structured by the form of judgement. I do not describe this thought as an idealism in my book, where I consider only idealisms of the sort I specify in the gloss Ayers omits, positions that insufficiently acknowledge the independence of reality. But the label is a good fit.

As I said, Ayers thinks the specification of a sort is redundant. He assumes that one cannot equate the form of the world and the form of thought without representing reality as a shadow of something self-standingly subjective. But this depends on assuming that in any such position the form of thought must be taken to be explicable first, before we even consider thought's bearing on reality, and only subsequently said to coincide with the form of the world. In such a view the form is supposed to be in place as informing thought, which is surely subjective, before one argues that it informs reality as well. And then the claim that it informs reality does look like a projection of something that was first in place as subjective on to what is supposed to be objective. But if we say the world is everything that can be truly thought to be the case, we imply no such thing. The image of a projection from a self-standing subjectivity gets no purchase 
if we insist, as we should, that thought and the world must be understood together. The form of thought is already just as such the form of the world. It is a form that is subjective and objective together, not primarily subjective and thereby supposedly objective - an order of priority that would unmask its claim to be objective as spurious in just the way Ayers envisages.

Here we have, at least programmatically, an idealism that does not diverge from common-sense realism. Given its claim to match common sense, it is appropriate that the slogan that expresses this idealism - "The world is everything that is the case" should be truistic, as I said, not an expression of some contentious metaphysics. ${ }^{18}$

It may be tempting to protest that if the idealism I am envisaging is supposed to coincide with common sense, we may as well stick with common sense. But as soon as we are alert to the way rational animals are marked out as special by their potential for self-determination, we need to acknowledge that our rationality enters into the possibility of describing ourselves as accepting what our senses give us. As I said, such locutions do not fit just any creature whose senses inform it of things. And idealism is to the point in explaining how such locutions work - how our senses provide something for us to accept, in such a way that, in the ideal case, we directly take in part of the objective world.

This in turn contributes to making it unmysterious that capacities to which it is essential that they can be exercised in self-determination can be capacities for thought at all, with the objective purport that implies. But that topic has not been on my agenda for this paper, and I shall take it no further here.

\footnotetext{
${ }^{18}$ Ayers misreads what he calls "McDowell's quietist patter" (op. cit., p. 253). He thinks the point of the "quietist patter" is to enable me not to mean it when I say the world is conceptually structured. ("We are not to suppose that talk of 'facts' means that the world ... is literally propositional in form ...": p. 254.) But I do mean it; the point of the "quietist patter" is not to take back the claim that the world is conceptually structured, but to insist that it does not express something metaphysically contentious. Ayers's blindness to the possibility of an idealism that is, if properly understood, uncontentious - his conviction that any idealism cannot but depreciate the independence of reality - leads him, at p. 255, to claim that it is "bad metaphysics" to suppose the world as we experience it breaks up into facts. He thinks this is the top of a slippery slope at the bottom of which lies the idea that reality, so called, is a projection from thought. (See also pp. 248-9.) He insists, here, on the contrasting thought that "the world, on the scale at which we experience it, is to an extent broken up into unitary material objects, and that is how we experience it". It is worth noting that this does not sit well with his approval, at p. 241, of the idea that "we just accept what the senses conjointly give". What it makes sense to say we accept is surely putative revelations by the senses of how things are. We do not accept unitary material objects; we accept, say, that we are confronted by them.
} 


\section{Bibliography}

Michael Ayers,"Sense experience, concepts, and content - objections to Davidson and McDowell”, in Ralph Schumacher, ed., Perception and Reality: From Descartes to the Present, Paderborn 2004, pp. 239-62.

Robert B. Brandom, Making It Explicit: Reasoning, Representing, and Discursive Commitment, Cambridge, Mass. 1994.

Tyler Burge, "Perceptual entitlement", Philosophy and Phenomenological Research (2003), pp. 503-48.

Arthur W. Collins, "Beastly experience”, Philosophy and Phenomenological Research (1998), pp. 375-80.

Donald Davidson, "A coherence theory of truth and knowledge", in Davidson, Subjective, Intersubjective, Objective, Oxford 2001, pp. 137-57.

Immanuel Kant, Critique of Pure Reason, translated by Norman Kemp Smith, London 1929.

John McDowell, "Having the world in view: Sellars, Kant, and intentionality", Journal of Philosophy (1998), pp. 431-91.

John McDowell, Mind and World, Cambridge, Mass. 1994.

John McDowell, "Reply to commentators", Philosophy and Phenomenological Research (1998), pp. 403-31.

Richard Rorty, "Solidarity or objectivity?", in Rorty, Objectivity, Relativism, and Truth, Cambridge 1991, pp. 21-34.

Richard Rorty, "The very idea of human answerability to the world: John McDowell's version of empiricism", in Rorty, Truth and Progress: Philosophical Papers, vol. 3, Cambridge 1998, pp. 138-52.

Ludwig Wittgenstein, Notebooks 1914-1916, Oxford 1961.

Ludwig Wittgenstein, Tractatus Logico-Philosophicus, London and Henley 1961. 